\title{
Procedimento e tratamento para evitar fissuras nas ligações entre alvenaria e estrutura de con- creto armado - Um estudo de caso
}

Title: Procedure and treatment to prevent cracks in the connections between masonry and structure of concrete armed - A study case

Diego Victor Siqueira Reis e Silva

Escola Politécnica de Pernambuco

Universidade de Pernambuco

50.720-001 - Recife, Brasil

diegovsrs@hotmail.com

\author{
Carlos Wellington Pires Sobrinho \\ Escola Politécnica de Pernambuco \\ Universidade de Pernambuco \\ 50.720-001 - Recife, Brasil \\ carlositep@gmail.com
}

Resumo As fissuras apresentadas nos encontros entre alvenaria e estrutura, é uma problemática bastante recorrente nos serviços de garantia das construtoras. Assim sendo, saber as causas de uma forma mais eficaz, é de extrema importância para determinação de quais métodos de recuperação ou reforço serão utilizados, a fim de melhorar o desempenho do empreendimento.

Palavras-Chave: fissura; alvenaria; estrutura; ligação; tela metálica; encunhamento

\footnotetext{
Abstract The cracks presented in meetings between masonry and structure, are a fairly frequent problem in guarantee of construction services. Thus, knowing the cause of a more effective manner, it is of extreme importance for determining which increase or recovery methods are used to improve the performance of the enterprise.
}

Keywords: fissure ; masonry; structure; link; metal screen ; wedging 


\section{Introdução}

As alvenarias são parte integrante do sistema da edificação, sendo muito utilizadas nos mais diversos tipos de construções como forma de vedação. No entanto, quando aplicada junto a outros elementos construtivos, esta pode passar a sofrer interferência de comportamento podendo apresentar problemas mesmo antes da entrega total do edifício.

Com a aceleração do crescimento imobiliário, o número de edificações tem crescido de maneira que o tempo de sua execução tem sido cada vez menor para atender a demanda de mercado de venda de imóveis. Aliado a isto, a execução dos sistemas construtivos vem sendo feita mais rapidamente, muitas vezes não respeitando as normas relativas ao tempo mínimo ao qual certos elementos devem ser aplicados.

Segundo Sabbatini [1], desde meados da década de setenta até o momento atual, as fissuras e trincas nas vedações em alvenaria de edifícios de multipavimentos com estrutura de concreto armado têm aumentado continuamente, em termos da frequência de manifestações, intensidade de ocorrências e gravidade.

Junto a esta problemática, o aparecimento de manifestações patológicas na ligação estrutura de concreto armado está surgindo de maneira recorrente. A aplicação de elementos que venham a absorver possíveis esforços que sejam transferidos para ela deve ser feita de modo que patologias dessa natureza sejam evitadas.

Diversos estudos, apontam o alto custo que as construtoras estão submetidas para correção de problemas ocorridos na pós entrega das obras. Valores estes, que não estão inclusos no orçamento inicial da obra, acarretando um estouro orçamentário. Como forma de prevenir patologias, é indispensável a correta execução de todos os serviços, desde a fundação até o acabamento, sempre buscando os procedimentos mais adequados.

Para isso, se faz necessário a exposição de meios para a correta execução dos serviços, reiterando a indispensabilidade de seguir os procedimentos citados em normas e com o intuito de evitar futuras patologias que possam vir a prejudicar o desempenho do elemento construtivo, durante a vida útil da edificação.

\section{Fissuras na ligação entre alvenaria e concreto armado}

Grande parte dos edifícios brasileiros, são executados com estrutura de concreto armado com a vedação em alvenaria tradicional, ou seja, alvenaria de blocos cerâmicos. A alvenaria aplicada junto à estrutura de concreto, passa a sofrer influência de carregamentos ou esforços os quais não são esperados. Além disso, existem as diferenças nas propriedades dos materiais, o que pode influenciar no surgimento de patologias, as quais podem comprometer ou não a utilização da edificação.

Sabbatini [1] afirma que a alvenaria cerâmica utilizada nos dias de hoje como vedação de edifícios, tem menor resistência à compressão e é mais rígida, ou seja, tem menor deformabilidade. Diz ainda que, mesmo antes da fixação superior, a alvenaria passa a interagir com a estrutura, devido ao peso desta, a estrutura de apoio tende a se deformar, o que passa a ser inibido pela alvenaria que, com o endurecimento da argamassa, já é um corpo rígido que reage contra a deformação do suporte, podendo apresentar, portanto, patologias.

Um tipo de patologia muito comum que ocorre no encontro entre os elementos citados, são as fissuras. Estas por sua vez podem ser evitadas através da introdução de elementos que distribuam melhor os esforços entre o concreto e a alvenaria, dissipando os esforços sem que haja comprometimento do ponto de vista estético. A importância desses elementos e o desenvolvimento de novas soluções para o reforço ou recuperação das fissuras, são temas bastante recorrentes na comunidade da construção civil. Entre as principais causas do aparecimento de fissuras, se destacam: movimentações térmicas; movimentações higroscópicas; recalque das fundações; deformações das estruturas de concreto armado (Figura $01)$.

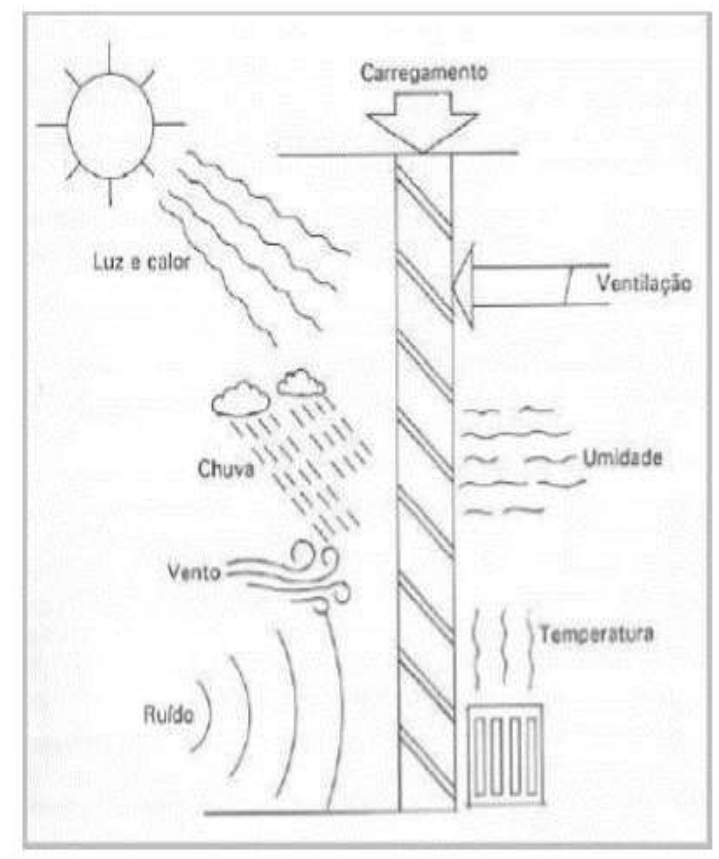

Figura 01: Solicitações impostas às superfícies das edificações (CINCOTTO et al, 1995 apud SAHADE, 2005)[2] 


\subsection{Movimentações térmicas}

As movimentações térmicas são ocasionadas por variação de temperatura atuando sobre os componentes da edificação, gerando uma variação nas suas dimensões. Com essa variação surgem tensões que ora são de tração ora de compressão, gerando tensões que podem vim a provocar fissuras.

Os elementos de coeficiente de dilatação térmica diferentes, como materiais cerâmicos e as estruturas de concreto, possuem comportamentos distintos. Além deste fator, a atuação diferenciada do calor do sol em pontos distintos aliada a gradientes de temperatura ao longo do mesmo componente podem levar ao aparecimento de fissuras[3].

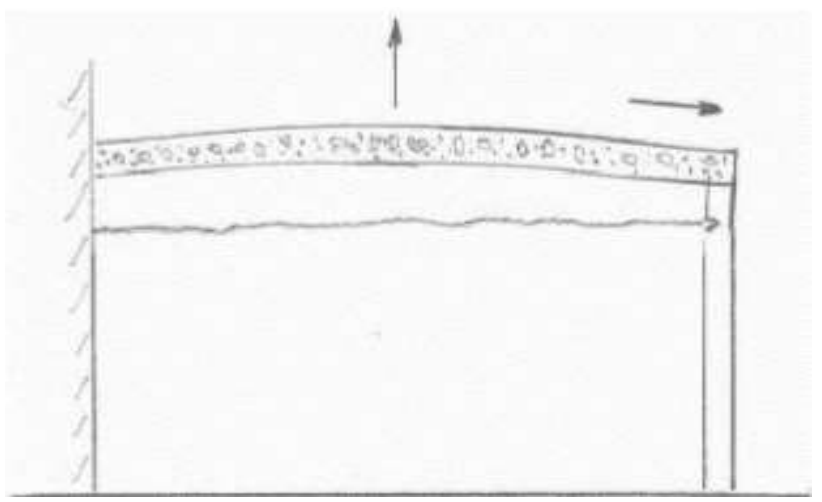

Figura 02: Fissuras de movimentação térmica (THOMAZ, 1989) [4]

\subsection{Movimentações higroscópicas}

As fissuras ocasionadas por esse tipo de movimentação se parecem bastante com as mencionadas anteriormente, entretanto as higroscópicas correspondem a dilatação ou contração relacionadas com a quantidade de água absorvida por um material de construção dependendo de sua porosidade e capilaridade.

Para este caso, o aumento do teor de umidade provoca uma expansão do material, enquanto que a diminuição desse teor provoca uma contração. Esses tipos de movimentações podem provocar destacamentos entre a alvenaria e a argamassa de assentamento, dependendo da intensidade da variação da umidade. Como exemplo, cita-se os alicerces das paredes que ficam em contato com o solo e absorvem a umidade do mesmo, provocando assim, o aparecimento de fissuras horizontais na parede [5].

\subsection{Recalque das fundações}

De acordo com as características do solo de assentamento das fundações, com a aplicação de carga, diferentes comportamentos podem ser obtidos. Deslocamentos verticais das fundações, chamados de recalque, pode ocorrer de duas formas: imediata ou ao longo do tempo (também chamado de adensamento). Contudo, ambos devem ser previstos em projetos.

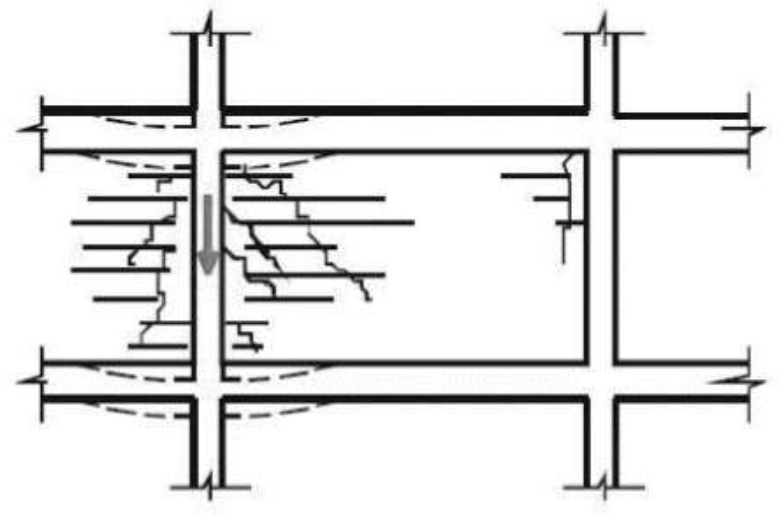

Figura 03: Fissuras ocasionadas por recalques diferenciais entre pilares

(THOMAZ, 1989) [4]

Em caso de haver deslocamentos não previstos ou excessivos e de diferentes extensões, pode-se ter o que se chama de recalque diferencial, ou seja, quando um elemento da fundação se desloca diferencialmente de outro, levando ao aparecimento de fissuras.

Além das propriedades do solo, a má compactação, pode gerar deformações plásticas e elásticas pois o mesmo sempre está sujeito a carregamentos. Com a movimentação do solo e consequente recalque das fundações, as fissuras que geralmente são inclinadas, aparecem principalmente nos pavimentos próximos ao térreo. Deve-se estar atento a gravidade do recalque, pois pode haver fissuração nos pavimentos superiores.

\subsection{Deformações das estruturas de concreto armado}

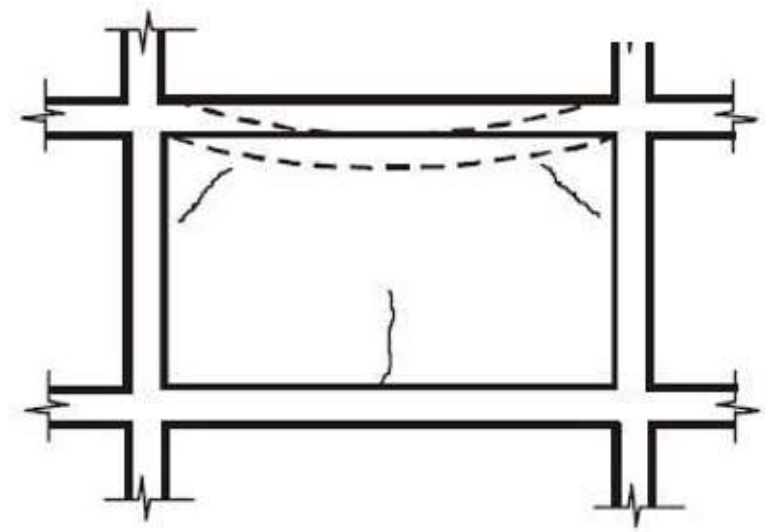

Figura 04: Fissuras ocasionadas pelas deformações das estruturas de concreto (DUARTE, 1998) [6]

Os componentes estruturais admitem flechas que podem não comprometer em nada sua própria estética, a estabilidade e a resistência da construção; tais flechas, 
entretanto, podem ser incompatíveis com a capacidade de deformação das paredes [4].

Com o aumento da esbeltez das estruturas, vãos cada vez maiores entre pilares, comprimentos extensos de vigas e dimensões reduzidas das seções dos pilares o concreto passa a permitir maiores deformações sem que haja prejuízo do ponto de vista estrutural e até mesmo estético. Sob esse ponto de vista a alvenaria aplicada sobre a estrutura de concreto acaba por receber cargas para as quais não foi dimensionada, podendo levar ao aparecimento de fissuras, as quais podem comprometer a utilização durante sua vida útil de projeto.

\section{Técnicas preventivas}

Em caso de obras executadas com maior velocidade, nas quais o intervalo de tempo entre concretagens de diferentes pavimentos é mínimo, as deformações do concreto podem atingir valores que podem levar ao aparecimento de sintomas patológicos.

Medidas relacionadas aos elementos que fazem o elo com a alvenaria, como as estruturas de concreto (pilares, veigas e lajes) podem evitar o aparecimento de patologias. Cuidados como o tempo mínimo de escoramento de lajes e vigas, o qual corresponde as deformações iniciais da estrutura e a cura adequada das peças concretadas, são fatos que podem reduzir o seu surgimento. No entanto, essas medidas não são suficientes para anular a presença de patologias.

\subsection{Ligação pilar/alvenaria}

De maneira geral, por ser uma área susceptível à fissuração, esta interface pode ser ligada por dispositivos que façam a ancoragem entre esses dois tipos de materiais. Para evitar o aparecimento dessas fissuras, algumas soluções são executadas, entre elas a utilização de ferro cabelo e da tela metálica, as quais são bastante eficazes e vem sendo utilizadas na construção civil brasileira.

No entanto, a técnica mais utilizada é a da tela metálica devido à produtividade e facilidade de sua aplicação. Para este caso algumas medidas preliminares devem ser adotadas para que este elemento apresente um bom desempenho. A primeira delas é fazer a limpeza da superfície na qual a tela será aplicada, a fim de remover resíduos que estejam na estrutura. Posteriormente, deve ser aplicado chapisco, que pode conter aditivos a fim de que se obtenha uma superfície com boa aderência. Dessa forma, deve-se aguardar por um período igual ou superior a 72 horas para que a tela possa aplicada [3].

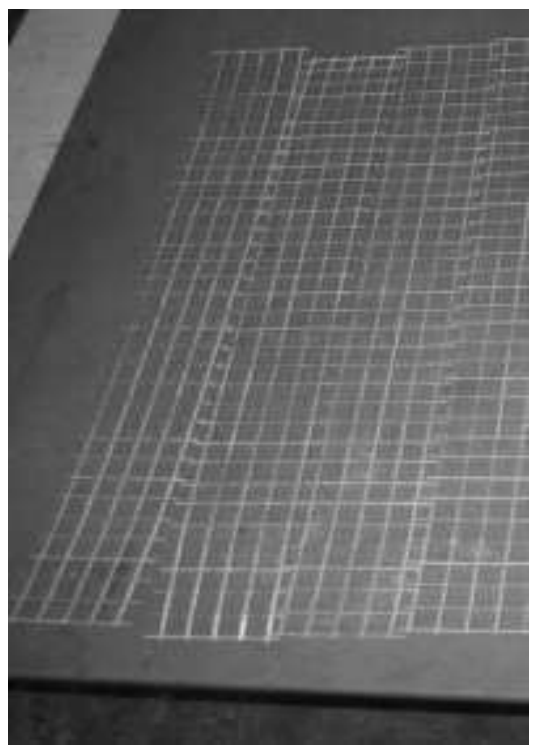

Foto 01: Tela metálica $9 \mathrm{~cm}$ x $50 \mathrm{~cm}$, com malha de $1,5 \mathrm{~cm}$

Quanto à aplicação, deve-se iniciar pela escolha correta das dimensões da tela, a qual deve ter um tamanho mínimo o qual obedeça a $30 \mathrm{~cm}$ de transpasse entre a alvenaria e o pilar, depois manter a ligação perpendicular à junta horizontal, lembrando de respeitar a largura do bloco a ser utilizado. O preenchimento correto e uniforme das juntas e a obediência aos itens citados acima, são as técnicas de prevenção mais utilizadas atualmente no Brasil, reduzindo significativamente o aparecimento de manifestações patológicas ligadas à fissuras nessa região de trabalho da edificação.

\subsection{Ligação Viga/Alvenaria}

Quando a alvenaria passa a ser aplicada sobre a estrutura de concreto armado, a união dos elementos faz com que as paredes passem a sofrer influência deste outro material, solidarizando seus esforços. Os deslocamentos e as deformações, sejam por flexão de vigas ou por encurtamento de pilares devido as cargas aplicadas gradualmente passam a ser restringidos pela alvenaria.

A atuação dos de cargas horizontais e verticais passam da estrutura de concreto para a alvenaria, a qual passa a sofrer os esforços daquelas, transmitindo-os de cima para baixo, e assim absorvem parte das movimentações impostas, ficando sob tensão.

Para o encontro das vigas com as alvenarias, podem ocorrer, devido ao carregamento que poderá passar a atuar sobre a alvenaria ou até mesmo pela diferença de materiais, a presença de fissuras. A colocação de argamassa expansiva no encunhamento da alvenaria, pode absorver as tensões ali contidas evitando que ocorram essas fissuras. Entretanto, também devem ser tomados alguns cuidados para que o seu desempenho não leve ao aparecimento de manifestações patológicas. 
As recomendações a serem seguidas são [3]:

- Retardar ao máximo possível a execução do encunhamento ou fixação para permitir a livre deformação inicial da estrutura de concreto;

- Executar o encunhamento ou fixação de cima para baixo, ou seja, dos pavimentos superiores para os inferiores, fazendo com que os pavimentos inferiores absorvam as deformações gradualmente. Quando a entrega da edificação é de curto prazo, pode-se adotar o encunhamento de pavimentos alternados;

- Realizar um intervalo entre o término da alvenaria de vedação e o encunhamento ou fixação de no mínimo duas semanas;

- Utilizar a bisnaga para aplicação garantindo uma camada de argamassa uniforme. Deve-se evitar colher de pedreiro para tal finalidade ;

Dessa forma, pode-se evitar que as fissuras possam vir a aparecer ao decorrer do carregamento e posteriormente ao uso da edificação.

\section{Tratamento de fissuras}

O aparecimento de fissuras na ligação entre alvenaria/pilar e/ou alvenaria/vigas pode ocorrer por diversos motivos. Devido a isto devem ser tomadas medidas e procedimentos que devem ser previstos na fase de projeto, a fim de que os elementos necessários sejam inseridos durante a execução da alvenaria e revestimentos de modo a minimizar o aparecimento das manifestações patológicas como as fissuras.

Contudo, em obras executadas sem projetos de alvenaria, sejam antigas ou recentes, e nas quais a execução dos padrões definidos em projetos não seja feita com procedimentos baseados em normas técnicas, o aparecimento dessas patologias ao longo do tempo e do uso da edificação pode ser praticamente inevitável.

Dessa forma, faz-se necessário aplicar técnicas de recuperação do local afetado. No entanto, a primeira etapa a ser executada deve ser a investigação da causa que venha a estar provocando o surgimento das fissuras, a qual é demonstrada através das manifestações que a peça construtiva apresenta.

No caso das fissuras apresentadas no alinhamento da ligação alvenaria/pilar e alvenaria/viga a patologia se desenvolve a partir de deficiência na fixação entre a alvenaria e a estrutura. Para o primeiro caso, em geral a patologia se aparece devido à ligação deficiente entre os dois elementos, como a falta de tela metálica fixada à estrutura, por exemplo. Já no segundo caso, no qual ocorrem fissuras horizontais, a problemática pode se dar pelo execução incorreta do encunhamento, seja pelo método utilizado ou pelo tempo inferior ao necessário de aplicação da argamassa de encunhamento.

Para ambos os casos a técnica de recuperação mais indicada é a aquela descrita em cinco etapas, sendo elas [7]:

- Remover o revestimento e limpar a área;

- Colocar argamassa polimérica com tela de poliéster, transpassando a fissura com $20 \mathrm{~cm}$ para cada lado;

- Recompor a área com argamassa polimérica, fazendo o acabamento;

- Esperar, mínimo, 21 dias, para proceder emassamento o pintura.

\section{Estudo de caso}

A edificação trata-se de um edifício de uso residencial, o qual consta de 01 (um) pavimento térreo, 01 (um) pavimento pilotis, 17 (dezessete) pavimentos tipo e 01 (um) pavimento coberta com salão de festas. A estrutura é em concreto armado com a vedação em alvenaria de bloco cerâmico $9 \mathrm{~cm} \times 19 \mathrm{~cm}$ x $19 \mathrm{~cm}$, em alguns casos ainda foi utilizado blocos cerâmicos com as dimensões $9 \mathrm{~cm} \times 14 \mathrm{~cm} \times 19 \mathrm{~cm}$.

A decisão de utilizar dois tipos de blocos diferentes no sentido de racionalizar a alvenaria, e de acordo com a modulação imposta em projeto, evitar a quebra e o desperdício de materiais cerâmicos.

Atualmente a obra encontra-se em fase de acabamento, não apresentando até o momento do estudo nenhum tipo de patologia referente ao encontro de estrutura de concreto armado com a alvenaria.

Desde o início da obra, as ancoragens entre alvenaria e estrutura foram feitas da forma correta, ou seja, utilizando-se telas metálicas nos encontros verticais, e aguardando o tempo para encunhamento das paredes para o qual foi utilizado argamassa expansiva.

Além destas medidas, na parte externa foi feita a aplicação de mastique elástico, o qual foi aplicado exatamente no encontro entre vigas e alvenaria, formando uma junta de dilatação horizontal.

A alvenaria foi construída baseada no projeto, o qual foi elaborado por empresa localizada na Região Metropolitana do Recife.

\subsection{Projeto para execução da alvenaria}

No projeto de alvenaria, pede-se a presença das telas metálicas nas interfaces entre alvenaria e estrutura. Elas estão marcadas com círculos e localizadas no encontro entre alvenaria e estrutura. 
Para este caso, os detalhes mostrados fazem menção à ligação vertical, ou seja entre pilar e alvenaria, determinando em quais paredes as telas deverão ser aplicadas.

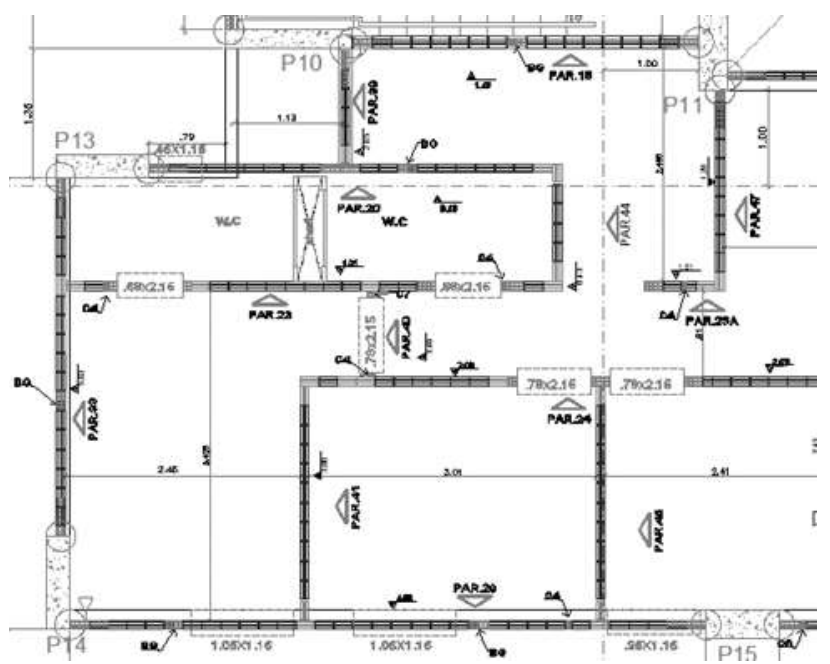

Foto 02: Projeto para execução da alvenaria
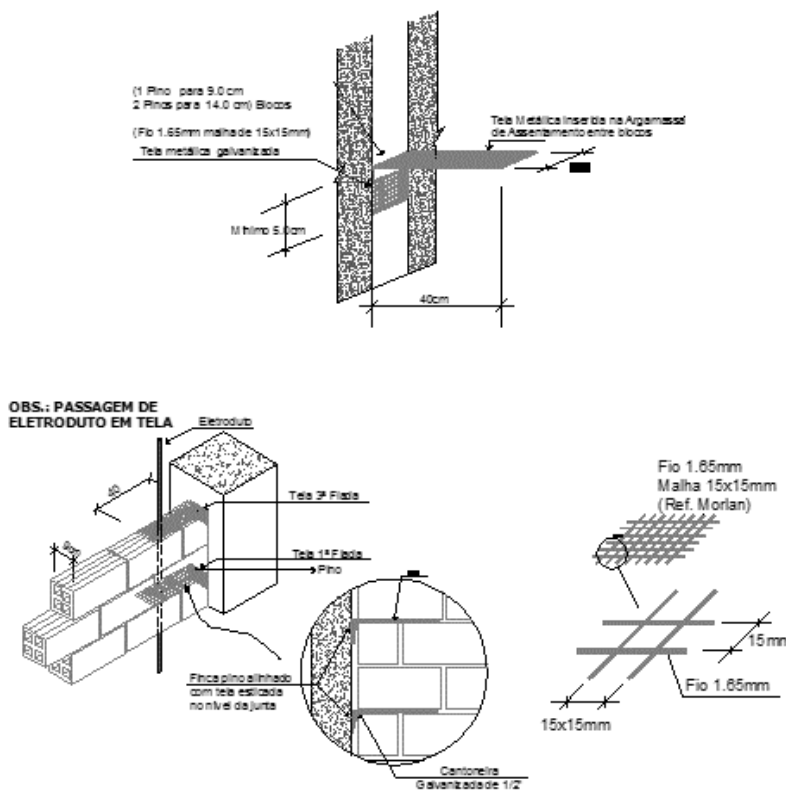

Foto 03: Detalhes da aplicação da tela metálica

A foto 03 representa os detalhes executivos da tela metálica e apresenta as especificações técnicas dos materiais que deverão ser utilizados, assim como a correta forma de aplicá-los.

A tela metálica galvanizada deverá ter uma malha de $15 \mathrm{~mm} \times 15 \mathrm{~mm}$ e dimensão de $9 \mathrm{~cm} \times 50 \mathrm{~cm}$. A indicação mostra que deve ser respeitado um transpasse mínimo da tela de $5 \mathrm{~cm}$ na ligação pilar/alvenaria , como esta dela deve ser fixada na estrutura de concreto para que haja transferência das solicitações sem que haja surgi, entre outras recomendações.

\subsection{Elevação da alvenaria}

A elevação da alvenaria é feita conforme o projeto, minimizando o aparecimento de patologias. Utilizando-se de pinos e uma pistola finca-pino, as telas metálicas são aplicadas em fiadas alternadas, ou seja, uma sim outra não. As mesmas são engastadas na estrutura de forma perpendicular à elevação.

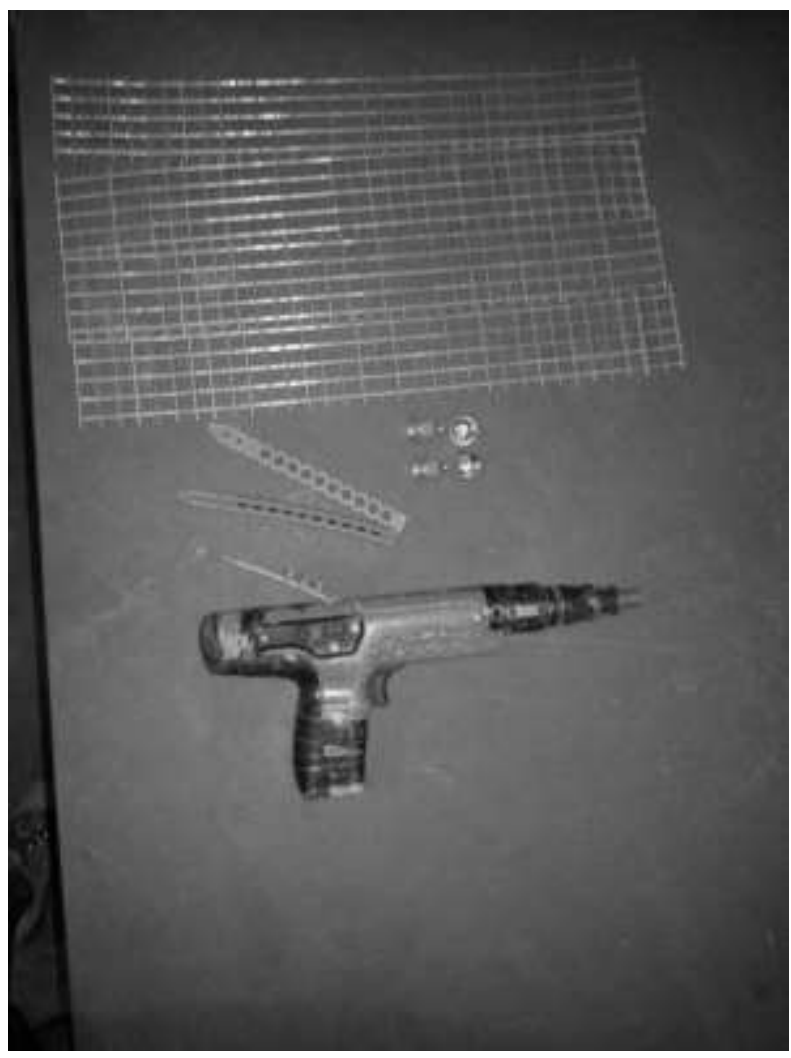

Foto 04: Telas metálicas e pistola para aplicação

Além do cuidado com a aplicação de elementos que absorvem as deformações transferidas da estrutura ou do seu deslocamento diferencial em relação a alvenaria, a obra optou por utilizar argamassa industrializada, de maneira que o traço seja uniforme, cabendo apenas ao betoneiro (profissional responsável pela preparação da argamassa utilizada) a adição de água.

Dessa forma, evitam-se possíveis erros que acontecem durante a medição dos elementos componentes do traço de argamassa. 


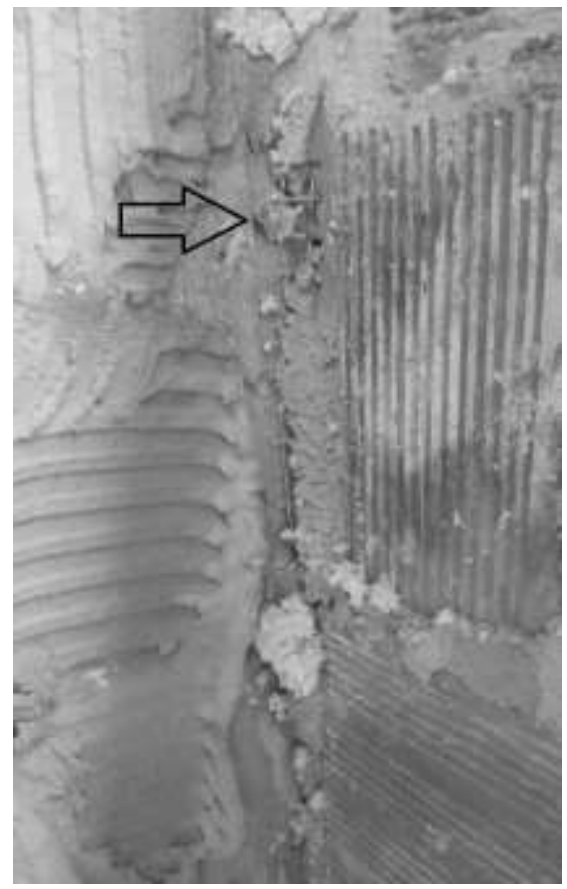

Foto 05: Telas metálicas na interface

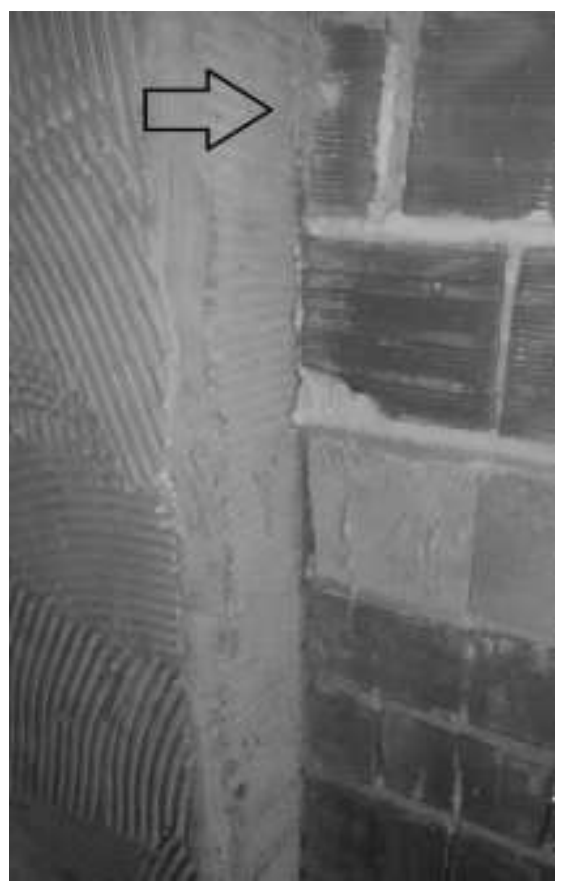

Foto 06: Telas metálicas na interface

\subsection{Encunhamento da alvenaria}

A obra andava em grande ritmo e não poderia esperar acabar toda a elevação do edifício para que fosse iniciado o encunhamento, tendo em vista que a não execução do mesmo impediria a aplicação do forro de gesso. Assim sendo, o encunhamento foi feito conforme determinação do consultor, o qual determinou da seguinte forma: quan- do a elevação da alvenaria chegou no pavimento 12 , foi realizado o encunhamento dos pavimentos 1 ao 8 , de cima para baixo; posteriormente, quando acabou a elevação foi executado o encunhamento dos demais pavimentos, também de cima para baixo, para que houvesse a acomodação dos esforços e fosse minimizado o risco de aparecimento de fissuras nesses pontos. Para execução do encunhamento, era utilizado um aditivo em pó, o qual era adicionado a argamassa conferindo-lhe propriedades expansivas, de modo a compensar a retração pela hidratação do cimento. Quando o espaço para encunhamento era pequeno, ainda se colocava as telas metálicas para auxiliar a acomodação dos esforços.

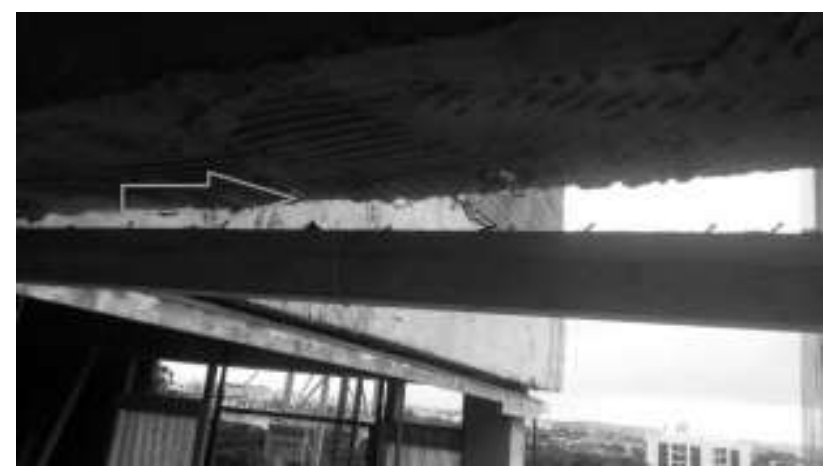

Foto 07: Telas metálicas para auxiliar no encunhamento

edificação.

\section{Conclusões}

Dentre as possíveis manifestações patológicas que a alvenaria pode apresentar, as fissuras entre este elemento e as estruturas de concreto armado são as que se apresentam de forma muito comum.

De acordo com a causa a partir da qual tem-se o aparecimento de patologias, é possível aplicar, durante a fase de construção, elementos que recebem as deformações e absorvem sem que haja o aparecimento e a degradação do revestimento aplicado.

O custo com a recuperação dos elementos, em geral é mais oneroso após estar sendo utilizado quando se compara com as medidas tomadas na fase de projeto e consequente execução.

Sendo assim, é possível inferir que a prevenção é a melhor opção no que diz respeito à aplicação de elementos que evitam o aparecimento de manifestações patológicas, tanto do ponto de vista de execução quanto de desempenho dos mesmos durante a utilização da edificação. 


\section{Referências}

[1] SABBATINI, F.H. et al. Vedações Verticais. Seminário Tecnologia e Gestão na Produção de Edifícios. Universidade de São Paulo. São Paulo. 1998.

CINCOTTO, M. A.; SILVA, M. A. C.; CAS-

[2] CAUDO, H. K. Argamassa de revestimento: características, propriedades e métodos de ensaio. São Paulo: Instituto de Pesquisas Tecnológicas, 1995.

[3] TEIXEIRA, C. H. Fissuras na interface da alvenaria de vedação com estruturas de concreto armado: Recomendações para Técnicas de Prevenção. Trabalho de conclusão de curso. Departamento de Engenharia Civil, Universidade do Rio Grande do Sul, Rio Grande do Sul, 64p.

[4] THOMAZ, E. Trincas em edifícios: causas prevenção e recuperação. São Paulo: Pini, 1989.

[5]

JODAS, M. Estudo das ligações entre pilares de concreto e alvenaria cerâmica de vedação. Dissertação de mestrado. Universidade Estadual Paulista. São Paulo, 2006.

[6] DUARTE, R. B. Fissuras em alvenarias: causas principais, medidas preventivas e técnicas de recuperação. Porto Alegre: CIENTEC, 1998. Boletim técnico n. 25.

[7] OLIVARI, Giorgio. Patologia em edificações. Trabalho de conclusão de curso. Departamento de Engenharia Civil, Universidade Anhembi Morumbi, São Paulo, 2009. 